University of Nebraska - Lincoln

DigitalCommons@University of Nebraska - Lincoln

Efficacy of Diatomaceous Earth to Control Internal Infestations of Rice Weevil and Maize Weevil (Coleoptera: Curculionidae)

Frank H. Arthur

USDA-ARS, frank.arthur@ars.usda.gov

James E. Throne

USDA-ARS, Manhattan, KS, james.throne@ars.usda.gov

Follow this and additional works at: https://digitalcommons.unl.edu/usdaarsfacpub

Arthur, Frank H. and Throne, James E., "Efficacy of Diatomaceous Earth to Control Internal Infestations of Rice Weevil and Maize Weevil (Coleoptera: Curculionidae)" (2003). Publications from USDA-ARS / UNL Faculty. 2024.

https://digitalcommons.unl.edu/usdaarsfacpub/2024

This Article is brought to you for free and open access by the U.S. Department of Agriculture: Agricultural Research Service, Lincoln, Nebraska at DigitalCommons@University of Nebraska - Lincoln. It has been accepted for inclusion in Publications from USDA-ARS / UNL Faculty by an authorized administrator of DigitalCommons@University of Nebraska - Lincoln. 


\title{
Efficacy of Diatomaceous Earth to Control Internal Infestations of Rice Weevil and Maize Weevil (Coleoptera: Curculionidae)
}

\author{
FRANK H. ARTHUR AND JAMES E. THRONE \\ Grain Marketing and Production Research Center, 1515 College Avenue, Manhattan, KS 66502
}

\begin{abstract}
J. Econ. Entomol. 96(2): 510-518 (2003)
ABSTRACT Densities of 10, 20, and 30 hard red winter wheat kernels, Triticum aestivum L., were infested with different life stages of the rice weevil, Sitophilus oryzae (L.), mixed with $35 \mathrm{~g}$ of wheat treated with $300 \mathrm{ppm}$ of the Protect-It (Mississauga, Ontario, Canada) formulation of diatomaceous earth (DE), and held at 22,27 , and $32^{\circ} \mathrm{C}$. A similar test was conducted by exposing densities of 6,12 , and 18 corn kernels infested with different life stages of the maize weevil, Sitophilus zeamais Motschulsky, mixed with $30 \mathrm{~g}$ of corn, Zea mays L., treated with $300 \mathrm{ppm}$ of DE. Mortality of adults emerging from kernels in wheat treated with $\mathrm{DE}$ was always greater than controls, and ranged from 56 to $90 \%$ at $22^{\circ} \mathrm{C}$ and was $>90 \%$ at 27 and $32^{\circ} \mathrm{C}$. In most treatment combinations, exposure to DE suppressed $\mathrm{F}_{1}$ progeny by $60-90 \%$ relative to untreated controls. Mortality of adult maize weevils on treated corn held at 22 and $27^{\circ} \mathrm{C}$ was lower than mortality of rice weevils on wheat, and ranged from 4 to $84 \%$. $\mathrm{F}_{1}$ production was low in corn held at $22^{\circ} \mathrm{C}$, and no $\mathrm{F}_{1} \mathrm{~s}$ were produced in either the controls or the treatments at $32^{\circ} \mathrm{C}$. In treated corn held at $27^{\circ} \mathrm{C}$, exposure to the DE suppressed $\mathrm{F}_{1}$ progeny by $\approx 70-80 \%$ relative to the untreated controls. Results of this study show that rice weevils and maize weevils emerging from infested kernels as adults are susceptible to DE, and these results are comparable to other studies in which adult weevils were exposed directly on wheat or corn treated with DE. Although adult weevils will be killed by exposure to DE, some oviposition could still occur and progeny suppression may not be complete; however, application of DE to commodities already infested with internal feeders, such as the rice weevil and the maize weevil, could help eliminate or suppress the infestation.
\end{abstract}

KEY WORDS stored grain, diatomaceous earth, maize weevil, rice weevil, Sitophilus, control

INSECT INFESTATIONS IN STORED grains and grain products can arise from several different sources, depending on the specific insect species. Some species can infest grain crops either in the field or after the crop has been cut and harvested (Cogburn and Vick 1981, Hagstrum 1985, Dix and All 1986). Trucks and railcars used to transport grain (Cogburn 1973), residual grain left in storage from previous years (Smith and Barker 1987), and the immediate environment around storage facilities are also important sources of infestations (Boon and Ho 1988; Throne and Cline 1989, 1991, 1994; Hagstrum et al. 1994; Dowdy and McGaughey 1994). Many stored-grain species are highly mobile and can quickly infest new grain after it is harvested and stored (Hagstrum 1989, Reed et al. 1991, Dowdy and McGaughey 1994, Arbogast and Throne 1997).

Grain crops stored in the United States are vulnerable to infestation from a variety of insect pest species. These insects are generally classified as external feeders, which develop outside the kernel, and internal

This paper reports the results of research only. Mention of a proprietary product or trade name does not constitute a recommendation or endorsement by the United States Department of Agriculture. feeders, which spend the majority of their immature stages inside the kernel. The rice weevil, Sitophilus oryzae (L.), is a pest of stored wheat, Triticum aestivum L., while the maize weevil, Sitophilus zeamais Motschulsky, is an important pest of stored corn, Zea mays L. Both are internal feeders; the females oviposit directly into the kernel, and the larvae hatch and develop inside the kernel until they reach the adult stage. Upon reaching the adult stage, these internal feeders exit by boring a hole in the kernel, resulting in an insect-damaged kernel.

In past years, control of rice weevils, maize weevils, and other stored-grain insect pests was achieved largely with conventional insecticides, and in many situations these chemicals are still an integral part of grain management. Protectant insecticides are either applied to the entire grain mass when it is loaded into a storage bin or silo, or applied as a surface treatment to the top of the grain after loading has been completed. As a result of changing consumer preferences, regulatory policies and decisions, and the economics of registering new compounds, the use, availability, and supply of grain protectants may decrease in the future (Longstaff 1994, Arthur 1996, Donahaye 2000). 
If infested grain is received, normal recommendations are to fumigate with phosphine instead of using a protectant, especially if the grain is infested with an internal feeder. Phosphine penetrates the grain kernel and kills the developing insect. Fumigation is also recommended if grain becomes infested during storage.

In recent years, there has been an increasing emphasis on using reduced-risk, low-toxicity insecticides in many agricultural systems, including stored grains, to control insect infestations. Inert dusts, including diatomaceous earth (DE), have received considerable attention (Golob 1997, Korunic 1998, Subramanyam and Roesli 2000). DE is composed of the fossilized cell walls of diatoms, and essentially causes dessication of insects through disruption of water transport through the epicuticle (Glenn et al. 1999). There are many formulations available both in the United States and throughout the world, and lists of commercial products can be found in several sources (Quarles and Winn 1994, Korunic 1998, Subramanyam and Roesli 2000).

If grain is sampled and found to be infested before storage, regardless of the source of the infestation, selective use of DE or other reduced-risk insecticides could eliminate the need for fumigation. Once grain is binned, insecticides can be applied to the grain surface, but if the infestation is present throughout the grain mass, the grain must be moved for treatment or fumigated inside the bin. If an insect infestation is confined to the grain surface, treatment of this specific target area may eliminate the need to fumigate the entire grain mass. External feeders in all life stages would be killed, but internal feeders developing inside grain kernels would not die until they emerged from the kernel and encountered the insecticide. However, this may be sufficient to stop population development. Currently, there are no published data concerning either the effect of DE on immature weevils developing inside the grain or on mortality of weevils emerging from the treated grain. The objectives of this test are to determine: 1) efficacy of DE on different stages of rice weevil developing inside wheat kernels and maize weevil developing inside corn kernels; and 2 ) reduction in subsequent $F_{1}$ progeny from adults exposed to DE after emergence.

\section{Materials and Methods}

Individual experimental units for the studies with wheat consisted of $35 \mathrm{~g}$ of wheat in 40 -ml vials. One gram of wheat contains $\approx 30$ kernels; therefore, each vial contained $\approx 1,050$ kernels. Tests were conducted at: 1) temperatures of 22,27 , and $32^{\circ} \mathrm{C} ; 2$ ) four life stages of immature weevils: small larvae (mostly first and second instars), medium-sized larvae (mostly third instars), large larvae (mostly fourth instars), and pupae; and 3) insect densities of 10, 20, or 30 infested kernels in $35 \mathrm{~g}$ of wheat in each vial. At each combination, there were four replicates of wheat treated with $300 \mathrm{mg} / \mathrm{kg}$ of the Protect-It formulation (Mississauga, Ontario, Canada) of DE, which is the labeled rate when used as a surface treatment, along with an untreated control. All tests were conducted at $57 \% \mathrm{RH}$ (intended in an equilibrium moisture content of $\approx 12.5 \%$ ), which was maintained by placing $\approx 750 \mathrm{ml}$ of saturated $\mathrm{NaBr}$ solution (Greenspan 1977) in each of three $26 \times 36.5 \times 15$-cm plastic boxes, with waffle-type grids in the bottom. Temperature and relative humidity inside the boxes were continually monitored using HOBO recording computers (Onset Computers, Pocasset, MA).

The first test was conducted at $27^{\circ} \mathrm{C}$, using large larvae. Standard rearing conditions for Sitophilus species are $\approx 27^{\circ} \mathrm{C}$ and $60 \% \mathrm{RH}$, and $\approx 6$ wk are required to complete the life cycle at this temperature- $\mathrm{RH}$ combination (Harein and Soderstrom 1966). To obtain large larvae, wheat kernels were selected from stock cultures that were 4 to 5 wk old. An x-ray procedure (Throne 1994) was used to locate infested kernels and to determine the size of the larvae. Briefly, this procedure involves placing individual kernels in a single layer on cellulose sheets coated with doublesided tape, then placing this sheet of kernels on radiographic film, and exposing the film for $4 \mathrm{~min}$ to an x-ray source (model 48355A, Faxitron; Hewlett-Packard, McMinnville, OR).

The individual experimental vials were prepared as follows. An average of $34.67 \mathrm{~g}$ of wheat was weighed into each of five vials, and then about half of the wheat in each vial was removed and placed into a second set of five vials. Ten kernels infested with large larvae were added to the first set of five vials, the wheat that had been removed from the vial was then returned, and the vial was hand-rolled for $\approx 30$ s to distribute the infested kernels throughout the wheat inside the vial. This procedure was repeated for the densities of 20 and 30 infested kernels by first weighing 34.33 and 34 $g$ respectively, of wheat into each of five vials, then subdividing the wheat, adding the appropriate number of infested kernels, and mixing the wheat, as described above.

One of the five vials at each density was removed to serve as an untreated control, and the remaining vials were treated at the rate of $300 \mathrm{ppm}$ of the Protect-It formulation of DE by taking each vial individually, removing about half of the wheat, adding $10.5 \mathrm{mg}$ of $\mathrm{DE}(10.5 \mathrm{mg} / 35 \mathrm{~g}$ is equivalent to $300 \mathrm{mg} / \mathrm{kg})$, pouring the wheat back into the vial, and hand-mixing for $\approx 30 \mathrm{~s}$ to distribute the DE evenly among the $35 \mathrm{~g}$ of wheat in the vial. The treated and control vials were placed into a plastic humidity box and held at $27^{\circ} \mathrm{C}$. After $3 \mathrm{wk}$, each vial was emptied into a pan, the emerged adult insects were removed, mortality of adults that had successfully emerged from the kernels was assessed, and the live and dead weevils were sexed according to characteristics of the snout (males of the genus Sitophilus generally have a blunter and shorter snout than females; Tolpo and Morrison 1965). The wheat was then put back into vials, returned to the humidity boxes, and held for an additional 8 wk at $27^{\circ} \mathrm{C}$, after which time the wheat was sifted again and the numbers of live and dead $F_{1}$ adults were recorded. 
This entire procedure was repeated on successive weeks by first selecting kernels from 5-wk-old stock cultures, repeating the $\mathrm{x}$-ray procedure to collect at least 60 kernels infested with pupae, then mixing, preparing, and treating the wheat, as described above. The vials were put in the humidity chambers and held for $2 \mathrm{wk}$, after which time wheat was sifted, mortality of adults that had successfully emerged from the kernels was assessed, and the live and dead weevils were sexed. The wheat was put back into the humidity chamber and the temperature incubator and held for 8 wk to collect $F_{1}$ adults, and the number of emerged $\mathrm{F}_{1}$ adults, both live and dead, was determined. During the next week, the procedures were repeated by selecting kernels from 2-wk-old stock cultures, collecting kernels infested with small larvae, preparing and treating the wheat as described, placing the vials in the humidity chamber, and holding the wheat for $5 \mathrm{wk}$ to collect adults from the infested kernels. Mortality was assessed, weevils were sexed, and the vials were held for $F_{1}$ adult emergence, as previously described. During the next week, tests were conducted with the remaining stage, medium-sized larvae, following all previously described procedures, except that the kernels were selected from 3-wk-old stock cultures, and vials were held for $4 \mathrm{wk}$ until the wheat was sifted. After the initial mortality assessments were made and weevils sexed, the wheat was held for 8 wk to record $F_{1}$ emergence. The tests were then repeated, first at 22 and then at $32^{\circ} \mathrm{C}$, in the following order: small larvae, middle-sized larvae, large larvae, and pupae.

Results of the study were analyzed with temperature, insect density, and life stage as main effects, using the analysis of variance (ANOVA) and general linear model (GLM) procedures of the Statistical Analysis System (SAS Institute 2000). Variables for analysis were the corrected initial mortality of weevils (Abbott 1925) after they emerged from the infested kernels and the percentage of reduction in $F_{1}$ adults. Percentage of reduction was determined by dividing the number of $F_{1}$ adults in the treated replicates by the number in the control vial for each life stage, subtracting this ratio from 1, and multiplying by 100 . A $t$-test was used to determine whether each value of adult mortality and each value of percentage of progeny reduction were $>0$ ( 0 indicates no response to $\mathrm{DE})$. A sequential Bonferroni analysis (Rice 1989) was used to determine significance of the $t$-values for the 12 observations within each temperature, resulting in a temperature-wise error rate of 0.05 . The correlation (CORR) procedure of SAS was used to determine whether the number of subsequent $F_{1}$ adults was dependent on the number of females that emerged from the original infested kernels.

At the conclusion of the test with wheat, a separate test was initiated with maize weevils corn. However, several modifications were necessary because of the size of the corn kernel compared with the wheat kernel. One gram of corn contains $\approx 3$ kernels, and the experimental unit was $30 \mathrm{~g}$ of corn in the $40-\mathrm{ml}$ vials, or a total of $\approx 90$ kernels of corn. The three temperatures $\left(22,27\right.$, and $\left.32^{\circ} \mathrm{C}\right)$ and the four categories of immatures (small larvae, medium-sized larvae, large larvae, and pupae) remained the same, but the insect densities were reduced to 6,12 , and 18 infested kernels per $30 \mathrm{~g}$ of corn. For each density level, 2, 4, and $6 \mathrm{~g}$ of infested kernels were combined with 28,26 , and $24 \mathrm{~g}$ of corn, respectively, for the total of $30 \mathrm{~g}$ in each experimental unit.

The $x$-ray procedure and the insecticide treatment remained the same as described for wheat, except that the application rate was changed to $9 \mathrm{mg}$ of DE per $30 \mathrm{~g}$ to obtain the label rate of $300 \mathrm{mg} / \mathrm{kg}$ for Protect-It as a surface treatment to stored grains. Tests were conducted in the order of 32,27 , and $22^{\circ} \mathrm{C}$, with each larval stage at weekly intervals over a 4 -wk period. Corn from stock cultures of different ages was selected to obtain kernels infested with each respective life stage, corn was prepared, seeded with infested kernels, and treated as described for wheat. The vials of corn containing kernels infested with small larvae, medium-sized larvae, large larvae, and pupae were placed inside the humidity chambers and in turn held in the temperature incubator for $5,4,3$, and $2 \mathrm{wk}$, respectively. The corn was then sifted, mortality was assessed, weevils were sexed as described for rice weevil, and the vials containing the corn were returned to the humidity chambers and the incubator and held for an additional 8 wk to record $F_{1}$ adult emergence. The statistical analysis was the same as described for wheat.

\section{Results}

The majority of rice weevils inside the infested kernels emerged as adults in untreated controls and in the wheat treated with DE (Table 1). Main effects temperature and life stage were significant in the treatments, but not density, nor any interaction, except for temperature and life stage (Table 1 footnotes). At densities of 20 and 30 infested kernels at $22^{\circ} \mathrm{C}$, and densities of 10 and 30 infested kernels at $27^{\circ} \mathrm{C}$, more young larvae died inside the kernels and failed to emerge compared with the other life stages (Table 1).

After the weevils emerged, there was little mortality $(0-10 \%)$ of adults from any of the life stages exposed in untreated wheat held at 22 and $27^{\circ} \mathrm{C}$, but mortality of emerged adults from kernels infested as small and medium-sized larvae ranged from 26.8 to $100 \%$, respectively, in untreated wheat held at $32^{\circ} \mathrm{C}$ (Table 2). In contrast, there was no mortality of adults emerging from kernels infested as large larvae and pupae in untreated wheat at $32^{\circ} \mathrm{C}$, indicating that the deleterious effects at $32^{\circ} \mathrm{C}$ were more extreme with the younger life stages of the rice weevil. Although small and medium-sized larvae held at $32^{\circ} \mathrm{C}$ were able to complete development inside the kernel and emerge as adults, they apparently died fairly quickly after emergence.

Mortality of adults emerging from the treated wheat ranged from 56 to $90 \%$ at $22^{\circ} \mathrm{C}$, and exceeded $90 \%$ in wheat held at 27 and $32^{\circ} \mathrm{C}$ (Table 2). All values for corrected mortality differed from 0 , showing a signif- 
Table 1. Percentage of mortality (failure to emerge, mean \pm SEM) of each life stage of rice weevil, at each density of 10 , 20, and 30 infested kernels, mixed with $35 \mathrm{~g}$ of wheat treated with $300 \mathrm{ppm}$ of $\mathrm{DE}$ and held at 22,27 , and $32{ }^{\circ} \mathrm{C}$; percentage of mortality of weevils in the control vial for each individual treatment is in parentheses

\begin{tabular}{|c|c|c|c|}
\hline \multirow{2}{*}{ Life stage } & \multicolumn{3}{|c|}{ Number of infested kernels } \\
\hline & 10 & 20 & 30 \\
\hline & \multicolumn{3}{|c|}{$22^{\circ} \mathrm{C}$} \\
\hline Small larvae & $15.0 \pm 0.5 \mathrm{a}(20)$ & $27.5 \pm 2.3 \mathrm{a}(15.0)$ & $25.8 \pm 6.2 \mathrm{a}(26.7)$ \\
\hline Medium-sized larvae & $2.5 \pm 2.5 \mathrm{a}(0)$ & $5.0 \pm 2.8 \mathrm{~b}(0)$ & $6.7 \pm 1.9 \mathrm{~b}(3.3)$ \\
\hline Large larvae & $5.0 \pm 2.8 \mathrm{a}(0)$ & $0 \pm 0.0 \mathrm{~b}(5.0)$ & $5.4 \pm 2.1 \mathrm{~b}(0)$ \\
\hline \multirow[t]{2}{*}{ Pupae } & $2.5 \pm 2.5 \mathrm{a}(0)$ & $0 \pm 0.0 \mathrm{~b}(0)$ & $0 \pm 0.0 \mathrm{c}(0)$ \\
\hline & \multicolumn{3}{|c|}{$27^{\circ} \mathrm{C}$} \\
\hline Small larvae & $12.5 \pm 2.5 \mathrm{a}(30)$ & $7.5 \pm 3.2 \mathrm{a}(0)$ & $15.0 \pm 5.2 \mathrm{a}(0)$ \\
\hline Medium-sized larvae & $0 \pm 5.0 \mathrm{~b}(0)$ & $2.5 \pm 2.5 \mathrm{a}(0)$ & $2.5 \pm 1.6 \mathrm{~b}(0)$ \\
\hline Large larvae & $0 \pm 0.0 \mathrm{~b}(0)$ & $2.5 \pm 1.4 \mathrm{a}(0)$ & $0.8 \pm 0.3 \mathrm{~b}(0)$ \\
\hline \multirow[t]{2}{*}{ Pupae } & $0 \pm 0.0 \mathrm{~b}(0)$ & $0 \pm 0.0 \mathrm{a}(0)$ & $0 \pm 0.0 \mathrm{~b}(0)$ \\
\hline & \multicolumn{3}{|c|}{$32^{\circ} \mathrm{C}$} \\
\hline Small larvae & $5.0 \pm 2.8(20)$ & $2.5 \pm 1.4(0)$ & $3.3 \pm 2.3(6.7)$ \\
\hline Medium-sized larvae & $2.5 \pm 2.5(0)$ & $2.5 \pm 2.5(0)$ & $3.7 \pm 3.6(0)$ \\
\hline Large larvae & $2.5 \pm 2.5(0)$ & $2.5 \pm 2.5(0)$ & $6.7 \pm 5.6(0)$ \\
\hline Pupae & $7.5 \pm 4.8(0)$ & $6.3 \pm 2.4(0)$ & $5.8 \pm 0.9(0)$ \\
\hline
\end{tabular}

ANOVA values for the treatments are as follows: temperature $(F=4.4 ; \mathrm{df}=2,108 ; P<0.02)$, life stage $(F=18.9 ; \mathrm{df}=3,108 ; F=0.01)$, density $(F=0.9 ; \mathrm{df}=2,108 ; P=0.42)$, temperature* $(F=8.6 ; \mathrm{df}=6,108 ; P=0.01)$, temperature* density $(F=0.5 ; \mathrm{df}=4,108 ; P=0.72)$, life stage* density $(F=0.6 ; \mathrm{df}=6,108 ; P=0.75)$, temperature* density* life stage $(F=1.0 ; \mathrm{df}=12,108 ; P=0.47)$. At $22^{\circ} \mathrm{C}$, densities of 20 and 30 infested kernels, and at $27^{\circ} \mathrm{C}$, densities of 10 and 30 infested kernels, more early larvae failed to emerge in the treatments compared with the other life stages $(P<0.05$, Waller-Duncan $k$-ratio $t$-test, significance denoted by different letters following the means).

icant DE effect at all treatment combinations. Although all tests were not conducted at the same time, an ANOVA was still performed on the results. Only the main effect temperature and the temperature density interaction were significant (Table 2 , footnotes). Mortality in the treatments appeared to be lower at $22^{\circ} \mathrm{C}$ than at 27 or $32^{\circ} \mathrm{C}$, but there was no obvious trend among the different densities or life stages.

The DE treatment did not result in complete progeny suppression, and $\mathrm{F}_{1}$ adults were produced at all life stage-density-temperature combinations in treated wheat, even when mortality of the original adults emerging from the infested kernels was 90$100 \%$ after $3 \mathrm{wk}$ (Table 3 ). The most likely reason for this was that mating and oviposition had occurred before the parent adults died. However, at each temperature there was a significant reduction in $\mathrm{F}_{1}$ progeny in most of the treatments as compared with the control. Main effects life stage and density were significant, but temperature and interactions were not

Table 2. Percentage of mortality (mean \pm SEM) of emerged adults from each life stage of rice weevils at each temperature and density level in wheat treated with $300 \mathrm{ppm}$ of $\mathrm{DE}$; percentage of mortality of weevils in the control vials for each individual treatment is in parentheses

\begin{tabular}{|c|c|c|c|}
\hline \multirow{2}{*}{ Life stage } & \multicolumn{3}{|c|}{ Number of infested kernels } \\
\hline & 10 & 20 & 30 \\
\hline & \multicolumn{3}{|c|}{$22^{\circ} \mathrm{C}$} \\
\hline Small larvae & $69.5 \pm 14.5(0)$ & $73.0 \pm 2.3(0)$ & $63.8 \pm 6.2(0)$ \\
\hline Medium-sized larvae & $84.0 \pm 8.6(0)$ & $75.0 \pm 6.1(0)$ & $75.9 \pm 6.3(0)$ \\
\hline Large larvae & $85.0 \pm 15.0(0)$ & $56.2 \pm 12.9(0)$ & $77.1 \pm 4.6(0)$ \\
\hline \multirow[t]{2}{*}{ Pupae } & $89.5 \pm 7.1(0)$ & $72.5 \pm 6.3(0)$ & $66.8 \pm 5.3(0)$ \\
\hline & \multicolumn{3}{|c|}{$27^{\circ} \mathrm{C}$} \\
\hline Small larvae & $100 \pm 0.0(0)$ & $100 \pm 0.0(5)$ & $99.0 \pm 0.0(3.3)$ \\
\hline Medium-sized larvae & $100 \pm 0.0(10)$ & $100 \pm 0.0(0)$ & $98.2 \pm 0.8(0)$ \\
\hline Large larvae & $100 \pm 0.0(0)$ & $100 \pm 0.0(0)$ & $99.0 \pm 0.0(0)$ \\
\hline \multirow[t]{2}{*}{ Pupae } & $100 \pm 0.0(0)$ & $100 \pm 0.0(0)$ & $100 \pm 0.0(0)$ \\
\hline & \multicolumn{3}{|c|}{$32^{\circ} \mathrm{C}$} \\
\hline Small larvae & $100 \pm 0.0(75)$ & $100 \pm 0.0(80)$ & $95.1 \pm 2.2(26.8)$ \\
\hline Medium-sized larvae & $a$ & $100 \pm 0.0(90)$ & $91.4 \pm 5.4(27.9)$ \\
\hline Large larvae & $100 \pm 0.0(0)$ & $97.5 \pm 1.4(0)$ & $98.1 \pm 1.0(0)$ \\
\hline Pupae & $100 \pm 0.0(0)$ & $100 \pm 0.0(0)$ & $98.1 \pm 0.9(0)$ \\
\hline
\end{tabular}

Percentage of mortality is based on the number of adults that successfully emerged from the kernels and died after emergence. Percentage of mortality in all of the treatments was significantly $>0$ using a sequential Bonferroni $t$-test with a temperature-wise error rate of 0.05 . ANOVA values for the treatments are as follows: temperature $(F=50.6 ; \mathrm{df}=2,108 ; P<0.01)$, life stage $(F=0.3 ; \mathrm{df}=3,108 ; P=0.84)$, density $(F=$ $0.8 ; \mathrm{df}=2,108 ; P=0.47)$, temperature* life stage $(F=1.1 ; \mathrm{df}=6,108 ; P=0.37)$, temperature* density $(F=2.5 ; \mathrm{df}=4,108 ; P=0.04)$, life stage* $^{*}$ density $(F=0.8 ; \mathrm{df}=6,108 ; P=0.61)$, temperature* density* life stage $(P=1.0 ; \mathrm{df}=12,108 ; P=0.41)$.

${ }^{a}$ Mortality of untreated controls was $100 \%$ in this treatment combination; hence, treatment mortality was not corrected or used in the analysis. 
Table 3. Percentage of reduction of $F_{1}$ adult rice weevils (mean \pm SEM) from the parent adults emerging from all life stages at each density and temperature, as compared with the number of $F_{1}$ adults in the control replicate (in parentheses)

\begin{tabular}{|c|c|c|c|}
\hline \multirow{2}{*}{ Life stage } & \multicolumn{3}{|c|}{ Number of infested kernels } \\
\hline & 10 & 20 & 30 \\
\hline & \multicolumn{3}{|c|}{$22^{\circ} \mathrm{C}$} \\
\hline Small larvae & $96.5 \pm 2.1(150)^{*}$ & $76.7 \pm 6.1(130)^{*}$ & $82.8 \pm 3.7(125)^{*}$ \\
\hline Medium-sized larvae & $86.4 \pm 2.9(83)^{*}$ & $61.7 \pm 4.2(120) *$ & $80.1 \pm 3.6(280)^{*}$ \\
\hline Large larvae & $84.1 \pm 4.0(98)^{*}$ & $66.0 \pm 5.2(125) *$ & $82.9 \pm 7.0(190)^{*}$ \\
\hline \multirow[t]{2}{*}{ Pupae } & $87.9 \pm 7.2(152) *$ & $-5.8 \pm 7.5(43)$ & $74.8 \pm 8.7(198) *$ \\
\hline & \multicolumn{3}{|c|}{$27^{\circ} \mathrm{C}$} \\
\hline Small larvae & $96.6 \pm 1.4(250)^{*}$ & $95.6 \pm 1.4(525) *$ & $95.9 \pm 1.4(600) *$ \\
\hline Medium-sized larvae & $88.3 \pm 4.7(250)^{*}$ & $79.1 \pm 5.1(300) *$ & $80.1 \pm 3.6(375)^{*}$ \\
\hline Large larvae & $97.7 \pm 1.3(600)^{*}$ & $87.3 \pm 5.7(420) *$ & $76.8 \pm 4.4(380)^{*}$ \\
\hline \multirow[t]{2}{*}{ Pupae } & $96.1 \pm 1.2(220)^{*}$ & $94.2 \pm 2.5(400) *$ & $83.0 \pm 4.9(250)^{*}$ \\
\hline & \multicolumn{3}{|c|}{$32^{\circ} \mathrm{C}$} \\
\hline Early larvae & $95.1 \pm 2.9(26)^{*}$ & $91.1 \pm 5.2(61) *$ & $95.3 \pm 2.5(113) *$ \\
\hline Medium-sized larvae & $60.0 \pm 25.6(15)$ & $71.1 \pm 14.2(38) *$ & $50.4 \pm 16.9(57)$ \\
\hline Large larvae & $88.4 \pm 4.8(180)^{*}$ & $57.8 \pm 14.5(80)$ & $50.8 \pm 10.0(130)^{*}$ \\
\hline Pupae & $72.9 \pm 5.4(84)^{*}$ & $44.1 \pm 4.1(162)^{*}$ & $27.6 \pm 15.1(125)$ \\
\hline
\end{tabular}

Percentage of $F_{1}$ reduction in the treatments is based on $F_{1}$ production in the control replicate. Within each temperature, a significant reduction in treatment $\mathrm{F}_{1} \mathrm{~s}$ as compared with the control, using a sequential Bonferroni $t$-test with a temperature-wise error rate of 0.05 , is denoted by an asterisk. ANOVA values for the treatments are as follows: temperature $(F=0.5 ; \mathrm{df}=2,108 ; P=0.47)$, life stage $(F=15.2 ; \mathrm{df}=$ $3,108 ; P<0.01)$, density $(F=35.5 ; \mathrm{df}=2,108 ; P<0.01)$, temperature* life stage $(F=9.9 ; \mathrm{df}=6,108 ; P=0.37)$, temperature* density $(F=$ $0.5 ; \mathrm{df}=4,108 ; P=0.68)$, life stage* density $(F=1.7 ; \mathrm{df}=6,108 ; P=0.15)$, temperature* density* life stage $(F=1.4 ; \mathrm{df}=12,108 ; P=0.19)$.

significant, and there were occasional differences in percentage of progeny suppression with respect to life stage (Table 3). At a density of 20 kernels infested with pupae at $22^{\circ} \mathrm{C}$, there were fewer progeny in the control compared with the treatments, which could be related to low $\mathrm{F}_{1}$ adults in that particular untreated control replicate. However, in wheat held at $32^{\circ} \mathrm{C}$, there was also a low percentage of progeny suppression when kernels were infested with pupae, which could indicate an extensive rate of oviposi- tion before the females died from exposure to the DE. There was no correlation between the number of parent females that emerged from the infested kernels and the subsequent number of $\mathrm{F}_{1}$ adults in either untreated $(r=-0.01, P=0.97)$ or treated wheat $(r=-0.12, P=0.21)$.

In contrast to rice weevil on wheat, there was a considerable amount of mortality of the various life stages of maize weevil in the infested kernels placed in untreated and treated corn, especially at 22 and

Table 4. Percentage of mortality (failure to emerge, mean \pm SEM) of each life stage of maize weevil, at each density of 6 , 12, and 18 infested kernels, mixed with $30 \mathrm{~g}$ of corn treated with $300 \mathrm{ppm}$ of $\mathrm{DE}$ and held at 22,27 , and $32^{\circ} \mathrm{C}$; percentage of mortality of weevils in the control vial for each individual treatment is in parentheses

\begin{tabular}{|c|c|c|c|}
\hline \multirow{2}{*}{ Life stage } & \multicolumn{3}{|c|}{ Number of infested kernels } \\
\hline & 6 & 12 & 18 \\
\hline & \multicolumn{3}{|c|}{$22^{\circ} \mathrm{C}$} \\
\hline Small larvae & $50.0 \pm 6.8 \mathrm{a}(33.3)$ & $43.7 \pm 2.1 \mathrm{a}(50.0)$ & $41.2 \pm 3.8 \mathrm{a}(50.0)$ \\
\hline Medium-sized larvae & $4.1 \pm 4.1 \mathrm{~b}(16.7)$ & $29.1 \pm 5.4 \mathrm{~b}(0)$ & $22.2 \pm 7.7 \mathrm{~b}(38.9)$ \\
\hline Large larvae & $33.3 \pm 11.7 \mathrm{a}(66.7)$ & $45.8 \pm 5.4 \mathrm{a}(58.8)$ & $48.6 \pm 6.9 \mathrm{a}(44.4)$ \\
\hline \multirow[t]{2}{*}{ Pupae } & $4.1 \pm 4.1 \mathrm{~b}(0)$ & $4.1 \pm 4.1 \mathrm{c}(8.3)$ & $9.7 \pm 4.7 \mathrm{~b}(0)$ \\
\hline & \multicolumn{3}{|c|}{$27^{\circ} \mathrm{C}$} \\
\hline Small larvae & $8.3 \pm 8.3 \mathrm{a}(50.0)$ & $25.0 \pm 3.4 \mathrm{a}(41.7)$ & $25.0 \pm 8.0 \mathrm{a}(27.8)$ \\
\hline Medium-sized larvae & $8.3 \pm 4.8 \mathrm{a}(16.7)$ & $27.1 \pm 7.9 \mathrm{a}(16.7)$ & $27.8 \pm 7.5 \mathrm{a}(22.2)$ \\
\hline Large larvae & $16.7 \pm 11.8 \mathrm{a}(33.3)$ & $35.4 \pm 7.1 \mathrm{a}(0)$ & $23.6 \pm 1.4 \mathrm{a}(0)$ \\
\hline \multirow[t]{2}{*}{ Pupae } & $0 \pm 0.0 \mathrm{a}(0)$ & $14.6 \pm 5.2 \mathrm{a}(16.7)$ & $1.4 \pm 1.4 \mathrm{~b}(0)$ \\
\hline & \multicolumn{3}{|c|}{$32^{\circ} \mathrm{C}$} \\
\hline Small larvae & $33.3 \pm 0.0 \mathrm{a}(66.7)$ & $33.3 \pm 5.9 \mathrm{~b}(33.3)$ & $38.9 \pm 8.8 \mathrm{~b}(22.2)$ \\
\hline Medium-sized larvae & $50.0 \pm 13.1 \mathrm{a}(50.0)$ & $31.2 \pm 3.9 \mathrm{~b}(23.3)$ & $27.8 \pm 4.5 \mathrm{~b}(44.4)$ \\
\hline Large larvae & $50.0 \pm 0.0 \mathrm{a}(50.0)$ & $43.7 \pm 7.1 \mathrm{~b}(25.0)$ & $44.4 \pm 7.1 \mathrm{~b}(27.8)$ \\
\hline Pupae & $50.0 \pm 0.6 \mathrm{a}(50.0)$ & $77.1 \pm 10.4 \mathrm{a}(66.7)$ & $83.3 \pm 4.5 \mathrm{a}(77.8)$ \\
\hline
\end{tabular}

ANOVA values for the treatments are as follows: temperature $(F=58.9 ; \mathrm{df}=2,108 ; P<0.01)$, life stage $(F=6.8 ; \mathrm{df}=3,108 ; P<0.01)$, density $(F=5.6 ; \mathrm{df}=2,108 ; P<0.01)$, temperature* life stage $(F=20.1 ; \mathrm{df}=6,108 ; P<0.01)$, temperature* density $(F=0.4 ; \mathrm{df}=4,108$; $P=0.84)$, life stage* density $(F=0.6 ; \mathrm{df}=6,108 ; P=0.75)$, temperature* density* life stage $(F=2.5 ; \mathrm{df}=12,108 ; P<0.01)$. For each temperature and density in the treatments, means followed by the different letters are significant $(P<0.05$, Waller-Duncan $k$-ratio $t$-test $)$ with respect to life stage. 
Table 5. Percentage of mortality (mean \pm SEM) of emerged adult maize weevils from each life stage at each temperature and density level in corn treated with $300 \mathrm{ppm}$ of $\mathrm{DE}$; percentage of mortality of weevils in the control vials for each individual treatment is in parentheses

\begin{tabular}{|c|c|c|c|}
\hline \multirow{2}{*}{ Life stage } & \multicolumn{3}{|c|}{ Number of infested kernels } \\
\hline & 6 & 12 & 18 \\
\hline $\begin{array}{l}\text { Small larvae } \\
\text { Medium-sized larvae } \\
\text { Large larvae } \\
\text { Pupae }\end{array}$ & $\begin{array}{l}37.6 \pm 14.3(0) \\
32.6 \pm 17.3(0) \\
43.8 \pm 7.5(0) \\
15.0 \pm 15.0(0)\end{array}$ & $\begin{array}{c}22^{\circ} \mathrm{C} \\
37.1 \pm 5.4(0) * \\
36.7 \pm 22.4(0) \\
8.1 \pm 4.9(0) \\
8.7 \pm 3.4(0)\end{array}$ & $\begin{array}{r}17.8 \pm 5.9(0) \\
4.2 \pm 4.2(0) \\
24.8 \pm 8.9(0) \\
9.7 \pm 2.4(0)\end{array}$ \\
\hline $\begin{array}{l}\text { Small larvae } \\
\text { Medium-sized larvae } \\
\text { Large larvae } \\
\text { Pupae }\end{array}$ & $\begin{array}{l}83.5 \pm 11.8(0) * \\
70.1 \pm 12.9(10) \\
33.4 \pm 18.0(0) \\
31.7 \pm 16.2(13.3)\end{array}$ & $\begin{array}{c}27^{\circ} \mathrm{C} \\
73.2 \pm 13.1(0) \\
50.4 \pm 17.5(0) \\
8.7 \pm 5.9(0) \\
13.9 \pm 5.5(0)\end{array}$ & $\begin{array}{l}68.0 \pm 10.4(0) * \\
34.4 \pm 18.7(0) \\
20.6 \pm 6.7(0) \\
11.5 \pm 1.8(4.4)\end{array}$ \\
\hline Pupae & & $32^{\circ} \mathrm{C}$ & \\
\hline $\begin{array}{l}\text { Small larvae } \\
\text { Medium-sized larvae } \\
\text { Large larvae } \\
\text { Pupae }\end{array}$ & $\begin{array}{l}93.9 \pm 6.3(0)^{*} \\
100 \pm 0.0(33.4) * \\
100 \pm 0.0(0)^{*} \\
100 \pm 0.0(0)^{*}\end{array}$ & $\begin{array}{l}87.8 \pm 7.9(11.1)^{*} \\
99.6 \pm 0(11.1)^{*} \\
96.1 \pm 3.5(0)^{*} \\
99.6 \pm 0.0(0)^{*}\end{array}$ & $\begin{array}{c}92.7 \pm 5.8(7.3)^{*} \\
94.5 \pm 2.1(11.1)^{*} \\
98.8 \pm 2.0(11.1)^{*} \\
100 \pm 0.0(0)^{*}\end{array}$ \\
\hline
\end{tabular}

Percentage of mortality is based on the number of adults that successfully emerged from the kernels and died after emergence. Within each temperature, percentage of mortality in an individual treatment that is significantly $>0$, using a sequential Bonferroni $t$-test with a temperaturewise error rate of 0.05 , is denoted with an asterisk. ANOVA values for the treatments are as follows: temperature $(F=178.1 ; \mathrm{df}=2,108 ; P<$ $0.01)$, life stage $(F=8.9 ; \mathrm{df}=3,108 ; P<0.01)$, density $(F=6.4 ; \mathrm{df}=2,108 ; P<0.01)$, temperature* life stage $(F=7.6 ; \mathrm{df}=6,108 ; P<0.01)$, temperature* density $(F=1.2 ; \mathrm{df}=4,108 ; P=0.32)$, life stage* density $(F=1.2 ; \mathrm{df}=6,108 ; P=0.30)$, temperature* density* life stage $(F=$ $0.4 ; \mathrm{df}=12,108 ; P=0.97)$.

$32^{\circ} \mathrm{C}$ (Table 4). All main effects, the temperature* life stage, and the temperature * life stage * density interaction were significant (Table 4 footnotes). At $22^{\circ} \mathrm{C}$, more weevils died in the treated corn when exposed as small or large larvae compared with medium-sized larvae or pupae, while at $32^{\circ} \mathrm{C}$ mortality was greatest in the pupal stage at densities of 12 and 18 infested kernels (Table 4).

There was little or no mortality $(0-13 \%)$ of adult maize weevils after emergence from any of the kernels infested with the four life stages in untreated corn held at 22 and $27^{\circ} \mathrm{C}$ (Table 5). Mortality did occur in adults emerging from corn kernels infested with small and medium-sized larvae and held at $32^{\circ} \mathrm{C}$, but never exceeded $34 \%$, and was generally much lower than mortality of the corresponding life stage of rice weevils in untreated wheat at $32^{\circ} \mathrm{C}$. Mortality of adult maize weevils from each of the life stages at each density level in treated corn was usually much lower than corresponding levels of mortality on wheat, and was generally not significantly $>0$, except at $32^{\circ} \mathrm{C}$ (Table 5 ), indicating that the DE may have been less effective on corn than on wheat. All main effects and the temperature * life stage interaction were significant, and percentage of corrected mortality appeared to increase with temperature.

Progeny production of maize weevils on untreated corn appeared to be far less than progeny production of rice weevils on untreated wheat, with few $\mathrm{F}_{1}$ adults (1-22) produced in corn held at $22^{\circ} \mathrm{C}$ and none in corn held at $32^{\circ} \mathrm{C}$ (Table 6). Because of the low numbers of $\mathrm{F}_{1}$ adults in controls at $22^{\circ} \mathrm{C}$ and the lack of $\mathrm{F}_{1}$ adults in controls at $32^{\circ} \mathrm{C}$, these data were eliminated from the statistical analysis. Consistent numbers of $F_{1}$ adults were produced in untreated corn held at $27^{\circ} \mathrm{C}$, except for one density-life stage combination. Exposure to the $\mathrm{DE}$ reduced $\mathrm{F}_{1}$ progeny compared with the untreated controls, but suppression was not complete and results were similar to those for rice weevil on wheat. Both main effects life stage and density, but not interaction, were significant (Table 6). There was no correlation between the number of female maize weevils that emerged from the infested corn kernels and the subsequent number of $\mathrm{F}_{1}$ adults in either treated $(r=-0.12, P=0.47)$ or untreated corn $(r=-0.01, P=$ $0.94)$.

\section{Discussion}

Stored-grain beetles vary widely in their susceptibility to inert dusts, including DE, and Sitophilus spe-

Table 6. Percentage of reduction of $F_{1}$ adult maize weevils (mean \pm SEM) from the parent adults emerging from all life stages at each density of 6,12 , and 18 kernels in corn held at $27^{\circ} \mathrm{C}$, as compared with the number of $F_{1}$ adults in the control replicate (in parentheses)

\begin{tabular}{lccc}
\hline \multicolumn{1}{c}{ Life stage } & 6 kernels & 12 kernels & 18 kernels \\
\hline Small larvae & $a$ & $81.7 \pm 5.5(60)$ & $81.5 \pm 2.7(88)$ \\
Medium-sized & $97.8 \pm 2.2(23)$ & $81.7 \pm 8.8(44)$ & $76.8 \pm 4.1(81)$ \\
$\quad$ larvae & & & \\
Large larvae & $71.7 \pm 8.4(30)$ & $72.5 \pm 8.5(45)$ & $82.2 \pm 4.7(76)$ \\
Pupae & $78.6 \pm 2.8(89)$ & $74.6 \pm 8.5(65)$ & $45.7 \pm 3.6(59)$ \\
\hline
\end{tabular}

Percentage of $F_{1}$ reduction in the treatments is based on $F_{1}$ production in the control replicate. There was a significant reduction in all $\mathrm{F}_{1} \mathrm{~s}$ in all treatments. ANOVA values for the treatments are as follows: life stage $(F=10.1 ; \mathrm{df}=3,36 ; P<0.01)$, density $(F=14.3$; $\mathrm{df}=2,36 ; P<0.01)$, life stage* density $(F=1.4 ; \mathrm{df}=6,36 ; P=0.23)$.

${ }^{a}$ Not included in analysis because only one progeny was produced in the control. 
cies are usually ranked midway in susceptibility to DE between small mobile insects, such as Cryptolestes spp. or Oryzaephilus spp., and the lesser grain borer (Rhyzopertha dominica F.) and Tribolium spp., which are more tolerant to inert dusts (Fields and Korunic 2000). In addition, differences in source origin, physical properties, and manufacturing characteristics can all contribute to variation in insecticidal efficacy among the various commercial formulations of DE (Korunic 1997, 1998). Therefore, it is often difficult to compare methods and results of different studies unless these studies have involved the same DE formulation and insect species, although the various species rankings are often consistent among different DE products (Fields and Korunic 2000). Consequently, there are few other studies that can be compared directly to ours.

Although recent reviews list and summarize data from a wide variety of tests and testing procedures (Korunic 1998, Subramanyam and Roesli 2000), most of the published studies focused on mortality of exposed insects and have not involved assessments of the impact of DE on progeny production, particularly when external feeders have been used in the tests. In Arthur (2002), exposure of 10, 20, and 30 mixed sex adult rice weevils for $1 \mathrm{wk}$ on wheat treated with 300 ppm Protect-It usually produced $100 \%$ mortality. However, the number of $F_{1}$ adults produced by these exposed parents at each density level in wheat held at $27^{\circ} \mathrm{C}$ and $57 \% \mathrm{RH}$ was $32.0 \pm 1.1,85.8 \pm 2.5$, and $83.7 \pm$ 7.7 , at each density level, respectively. These results were similar to the number of $F_{1}$ adults produced at $27^{\circ} \mathrm{C}$ and $57 \% \mathrm{RH}$ in our current test, and although the numbers in both tests represent a reduction from untreated control replicates, $\mathrm{F}_{1}$ adults were produced in the treatments even when mortality of exposed parents was ultimately $100 \%$ after $3 \mathrm{wk}$.

Reproduction and fecundity of maize weevils on corn were far lower compared with rice weevils on wheat, even in the untreated controls. Corn kernels are much larger than wheat kernels; the number of kernels of wheat and corn in the test vials were $\approx 1,050$ and 90 for each commodity, respectively. Therefore, fewer $F_{1} s$ would be expected from maize weevils on corn compared with rice weevils on wheat, because usually only one weevil can complete development inside a kernel. Also, at $32^{\circ} \mathrm{Cno} \mathrm{F}_{1}$ maize weevils were found in either the untreated controls or the corn treated with DE. Maize weevils may be more cold tolerant and less heat tolerant compared with rice weevils (Nakakita and Ikenaga 1997), and $32^{\circ} \mathrm{C}$ is nearing the upper developmental threshold for maize weevil on corn (Throne 1994).

Even with this reduced development of maize weevils on corn, our study showed that DE treatments may be less effective on corn than on wheat. Although neither the wheat nor the corn used in this study was actually equilibrated to the desired moisture content, results from other studies using saturated salt solutions have documented consistent inverse relationship between RH and mortality of insects exposed on DEtreated grains (Perez-Mendoza et al. 1999, Arthur
2002). Reductions in efficacy of DE on corn compared with wheat have been made by Subramanyam et al. (1994) and by Subramanyam and Roesli (2000) in reference to unpublished data, and they state that the differences in lipid and starch content of corn may be responsible for the loss of activity. Therefore, any relative difference in equilibrium moisture content of the DE-treated corn and wheat used in this study may have had little actual effect on mortality of exposed weevils, and would seem to indicate that results for DE trials on one commodity may not necessarily be transferrable to other commodities.

Most grain protectants have little effect on weevils developing inside the kernels, and this test with DE produced similar results. There was some mortality of immature stages in the kernels embedded in the DE treatments, but there were no clear trends and effects with respect to any of the four age classes that were used in this study. Although adult rice weevils and maize weevils emerging from these kernels were eventually killed by exposure to DE, exposed parents reproduced and laid eggs before they were killed. In tests with adult granary weevils, Sitophilus granarius (L.), an internally feeding weevil that does not fly and therefore has limited ability to escape exposure to insecticides, applications of 2,000 ppm of Fossil Shield DE (Fossil Shield Co., Berlin, Germany) killed adults, but also did not completely prevent progeny production (Mewis and Ulrichs 2001b). Populations of succeeding generations may be reduced, because as each generation emerges, parental mortality will occur, and the resulting effects on progeny production could slowly eliminate the population. However, there are no accepted standards as to what level of population could be termed acceptable. DE is effective against larvae of some secondary and external feeders (Subramanyam et al. 1998, Mewis and Ulrichs 2001a), so a greater degree of population suppression may be achieved when external feeders are infesting grain as compared with Sitophilus spp.

In our study, developing progeny of rice weevils were not directly exposed to DE, but instead encountered the DE on the surface of the wheat after they emerged as adults. The DE had little impact on the weevils developing inside the kernel, but upon emergence they were killed by direct exposure. Our results were similar to the other studies (Fields and Korunic 2000, Arthur 2002) in which rice weevils were exposed as adults on wheat treated with DE. In addition, mortality was usually lower at $22^{\circ} \mathrm{C}$ compared with 27 and $32^{\circ} \mathrm{C}$, which was also expected and consistent with previous results. In tests in which the red flour beetle, Tribolium castaneum (Herbst), and the confused flour beetle, Tribolium confusum (Jacquelin DuVal), were exposed on filter paper to Protect-It at the rate of 5 $\mathrm{g} / \mathrm{m}^{2}$, mortality of both species increased as temperature increased from 22 to 27 and then to $32^{\circ} \mathrm{C}$ (Arthur 2000). These consistent positive effects of temperature on the efficacy of DE probably result from the fact that insect movement increases as temperature increases, thereby resulting in more contact with the DE and a subsequent increase in mortality, and also a 
greater water loss at higher temperatures. Temperature effects as related to the efficacy of DE products are apparently somewhat variable among common stored-grain beetle species (Fields and Korunic 2000, Arthur 2002).

The ecosystem approach (Dunkel 1992, White 1992) and the concept of integrated pest management (IPM) are being advocated for stored grain, although the strategies may be different from those used in field crops (White 1992, Hagstrum et al. 1999, Phillips et al. 2000). Components of an IPM strategy to control insects in stored grain may include some or all of the following strategies: prebinning residual spray treatments; some use of protectants; aeration with lowvolume ambient air to cool the internal grain mass to temperatures that will not support insect growth; sampling and trapping to monitor insect populations; and fumigations with phosphine to immediately eliminate an infestation (Hagstrum et al. 1999, Phillips et al. 2000). Selective use of DE may also be part of IPM strategies, but control of internal feeders may not occur as quickly nor provide the degree of progeny suppression as would be achieved through the use of conventional insecticides. Perhaps DE could be combined with other insecticides to enhance population suppression of internal feeders in stored grain. Desiccant dusts have been shown to increase the toxic effects of the fungus Beauveria bassiana (Balsamo) on several beetle pests of stored grain (Lord 2001), and other combinations with reduced-risk insecticides or biological insecticides may help increase progeny suppression of internal grain pests.

\section{Acknowledgments}

We thank C. K. Hoernemann and A. L. Redmon for their excellent technical assistance with the research. Hedley Technologies supplied the DE used in these studies. We also thank P. G. Fields and D. K. Weaver for reviewing the manuscript before journal submission.

\section{References Cited}

Abbott, W. S. 1925. A method of computing the effectiveness of an insecticide. J. Econ. Entomol. 18: 265-267.

Arbogast, R. T., and J. E. Throne. 1997. Insect infestation of farm-stored maize in South Carolina: towards characterization of a habitat. J. Stored Prod. Res. 33: 187-198.

Arthur, F. H. 1996. Grain protectants: current status and prospects for the future. J. Stored Prod. Res. 32: 293-302.

Arthur, F. H. 2000. Toxicity of diatomaceous earth to red flour beetles and confused flour beetles: effects of temperature and relative humidity. J. Econ. Entomol. 93: $526-532$.

Arthur, F. H. 2002. Survival of Sitophilus oryzae (L.) on wheat treated with diatomaceous earth: impact of biological and environmental parameters on product efficacy. J. Stored Prod. Res. 38: 305-313.

Boon, K. S., and S. H. Ho. 1988. Factors influencing the post-fumigation reinfestation of Tribolium castaneum (Herbst) (Coleoptera: Tenebrionidae) in a rice warehouse. J. Stored Prod. Res. 24: 87-90.
Cogburn, R. R. 1973. Stored-product insect populations in boxcars delivering flour and rice to Gulf coast ports. Environ. Entomol. 2: 427-431.

Cogburn, R. R., and K. W. Vick. 1981. Distribution of Angoumois grain moth, almond moth, and Indianmeal moth in rice fields and rice storages in Texas as indicated by pheromone-baited adhesive traps. Environ. Entomol. 10: 1003-1007.

Dix, D. E., and J. N. All. 1986. Population density and sex ratio dynamics of overwintering maize weevils (Coleoptera: Curculionidae) infesting field corn. J. Entomol. Sci. 21: $368-375$.

Donahaye, E. J. 2000. Current status of non-residual control methods against stored product pests. Crop Prot. 19: 571576.

Dowdy, A. K., and W. H. McGaughey. 1994. Seasonal activity of stored-product insects in and around farm-stored wheat. J. Econ. Entomol. 87: 1351-1358.

Dunkel, F. V. 1992. The stored grain ecosystem: a global perspective. J. Stored Prod. Res. 28: 73-87.

Fields, P., and Z. Korunic. 2000. The effect of grain moisture content and temperature on the efficacy of diatomaceous earths from different geographical locations against stored-product beetles. J. Stored. Prod. Res. 36: 1-13.

Glenn, D. M., G. J. Puterka, T. Vanderwet, R. E. Byers, and C. Feldhake. 1999. Hydrophobic particle films, a new paradigm for suppression of arthropod pests and plant diseases. J. Econ. Entomol. 92: 759-771.

Golob, P. 1997. Current status and future perspectives for inert dusts for control of stored product insects. J. Stored Prod. Res. 33: 69-79.

Greenspan, L. 1977. Humidity fixed points of binary saturated aqueous solutions. J. Res. Nat. Bur. Stand. Physics and Chemistry 81A: 89-96.

Hagstrum, D. W. 1985. Preharvest infestation of cowpeas by the cowpea weevil (Coleoptera: Bruchidae) and population trends during storage in Florida. J. Econ. Entomol. 78: $358-361$.

Hagstrum, D. W. 1989. Infestation by Cryptolestes ferrugineus (Coleoptera: Cucujidae) of newly harvested wheat stored on three Kansas farms. J. Econ. Entomol. 82: 655659.

Hagstrum, D. W., A. K. Dowdy, and G. E. Lippert. 1994. Early detection of insects in stored wheat using sticky traps in bin headspace and prediction of infestation level. Environ. Entomol. 23: 1241-1244.

Hagstrum, D. W., C. Reed, and P. Kenkel. 1999. Management of stored wheat insect pests in the USA. Integrated Pest Mgt. Rev. 4: 127-142.

Harein, P. K., and E. L. Soderstrom. 1966. Coleoptera infesting stored products, pp. 241-259. In C. N. Smith (ed.) Insect colonization and mass production. Academic, New York.

Korunic, Z. 1997. Rapid assessment of the insecticidal value of diatomaceous earths without conducting bioassays. J. Stored Prod. Res. 33: 219-229.

Korunic, Z. 1998. Diatomaceous earths, a group of natural insecticides. J. Stored Prod. Res. 34: 87-97.

Longstaff, B. C. 1994. The management of stored product pests by non-chemical means: an Australian perspective. J. Stored Prod. Res. 30: 179-185.

Lord, J. C. 2001. Desiccant dusts synergize the effect of Beauveria bassiana (Hyphomycetes: Moniliales) on stored-grain beetles. J. Econ. Entomol. 94: 367-372.

Mewis, I., and C. Ulrichs. 2001a. Action of amorphous diatomaceous earth against different stages of the stored product pests Tribolium confusum, Tenebrio molitor, Sito- 
philus granarius and Plodia interpunctella. J. Stored Prod. Res. 37: 153-164.

Mewis, I., and C. Ulrichs. 2001b. Effects of diatomaceous earth on water content of Sitophilus granarius (L.) (Col.: Curculionidae) and its possible use in stored product protection. J. Appl. Entomol. 125: 351-360.

Nakakita, H., and H. Ikenaga. 1997. Action of low temperature and physiology of Sitophilus zeamais Motschulsky and Sitophilus oryzae (L.) (Coleoptera: Curculionidae) in rice storage. J. Stored Prod. Res. 33: 31-38.

Phillips, T. W., R. C. Berberet, and G. W. Cuperus. 2000. Post-harvest integrated pest management, pp. 2690-2701. In F. J. Francis (ed.), The Wiley encyclopedia of food science \& technology. Wiley, New York.

Quarles, W., and P.S. Winn. 1994. Diatomaceous earth and stored product pests. IPM Practitioner 18: 1-10.

Perez-Mendoza, J., J. E. Baker, F. H. Arthur, and P. W. Flinn. 1999. Effects of Protect-It on efficacy of Anisopteromalus calandrae (Hymeoptera: Pteromalidae) parasitizing rice weevils (Coleoptera: Curculionidae) in wheat. Environ. Entomol. 28: 529-534.

Reed, C. R., V. F. Wright, T. W. Mize, J. R. Pedersen, and J. B. Evans. 1991. Pitfall traps and grain samples as indicators of insects in farm-stored wheat. J. Econ. Entomol. 84: 1381-1387.

Rice, W. R. 1989. Analyzing tables of statistical tests. Evolution 43: 223-225.

SAS Institute. 2000. The SAS System version 7 for windows. SAS Institute, Cary, NC.

Smith, L. B., and P. S. Barker. 1987. Distribution of insects found in granary residues in the Canadian prairies. Can. Entomol. 119: 873-880.

Subramanyam, B., and R. Roesli. 2000. Inert dusts, pp. 321379. In B. Subramanyam and D. W. Hagstrum (eds.), Alternatives to pesticides in stored-product IPM. Kluwer Academic Publishers, Boston, MA.
Subramanyam, B., C. L. Swanson, N. Madamanchi, and S. Norwood. 1994. Effectiveness of Insecto ${ }^{\circledR}$, a new diatomaceous earth formulation, in suppressing several storedgrain insect species, pp. 650-659. In E. Highley, E. J. Wright, J. H. Banks, and B. R. Champ (eds.), Proceedings, 6th International Working Conference on Stored-Product Protection, 17-23 April 1994, CAB International, Wallingford, UK.

Subramanyam, B., N. Madamanchi, and S. Norwood. 1998. Effectiveness of Insecto applied to shelled maize against stored-product insect larvae. J. Econ. Entomol. 91: 280286.

Throne, J. E. 1994. Life history of immature maize weevils (Coleoptera: Curculionidae) on corn stored at constant temperatures and relative humidities in the laboratory. Environ. Entomol. 23: 1459-1471.

Throne, J. E., and L. D. Cline. 1989. Seasonal flight activity of the maize weevil, Sitophilus zeamais Motschulsky (Coleoptera: Curculionidae), and the rice weevil, S. oryzae (L.), in South Carolina. J. Agric. Entomol. 6: 183-192.

Throne, J. E., and L. D. Cline. 1991. Seasonal abundance of maize and rice weevils (Coleoptera: Curculionidae) in South Carolina. J. Agric. Entomol. 8: 93-100.

Throne, J. E., and L. D. Cline. 1994. Seasonal flight activity and seasonal abundance of selected stored-product Coleoptera around grain storages in South Carolina. J. Agric. Entomol. 11: 321-338.

Tolpo, N. C., and E. O. Morrison. 1965. Sex determination by snout characteristics of Sitophilus zeamais Motschulsky. Texas J. Sci. 17: 122-124.

White, N.D.G. 1992. A multidisciplinary approach to stored-grain research. J. Stored Prod. Res. 28: 127-137.

Received for publication 13 May 2002; accepted 16 October 2002 